\title{
Activity patterns of juvenile penaeid prawns in response to artificial tidal and day-night cycles: a comparison of three species
}

\author{
D. J. Vance \\ CSIRO Division of Fisheries, Marine Laboratories, PO Box 120, Cleveland, Queensland 4163, Australia
}

\begin{abstract}
Activity patterns of Penaeus merguiensis, $P$. esculentus and Metapenaeus endeavouri were studied in response to simulated tidal and day-night cycles in the laboratory. When these cycles were imposed separately, each species was more active at night and near the times of high tide. However, when the tidal and day-night cycles were imposed together, the relative strengths of the responses to the 2 factors differed among species. $M$. endeavouri was strongly influenced by the day-night cycle; virtually no activity occurred during the day but peaks of activity at night occurred near high tide. $P$. merguiensis and $P$. esculentus displayed some activity during the day with peaks around and just after high tide. However, for these 2 species, the peaks of activity near high tide at night were higher than the peaks during the day. All species were more active at night and, in the prawn's natural habitat, there is probably less risk of predation involved in being active at this time. Highest activity occurred near high tide and in the wild this is probably associated with feeding for all species. Decreased activity occurred at low tide, probably to avoid predation and, at times, dessication. The overall activity level of $P$. merguiensis was the highest of these species. The highest activity levels recorded for each species were similar but the lowest levels varied markedly. $M$. endeavouri remained buried for many hours during the day, whereas the lowest mean activity levels recorded for $P$. merguiensis were relatively high compared with the other species.
\end{abstract}

\section{INTRODUCTION}

The catch rates of penaeid prawns within a $24 \mathrm{~h}$ period are often extremely variable. A knowledge of this short-term variability is important in designing sampling strategies to estimate long-term changes in prawn abundance. As part of a study on the prawn fisheries of the Gulf of Carpentaria, Australia, the catchability of juveniles of several of the main commercial species was investigated in the Embley River (Vance \& Staples 1992). Statistical analysis of the catch variation of juvenile Penaeus merguiensis, $P$. esculentus and Metapenaeus endeavouri showed that, in general, catches of these species were greater at night and at lower tide levels. There were, however, differences in the relative importance of each factor. P. merguiensis catches were most strongly related to the daily tidal cycle: catches were highest on the last stage of the ebb tide having the greater range of the 2 daily tides, irre- spective of the day-night cycle. $M$. endeavouri was dominated by the day-night cycle: virtually no prawns were caught during the day. Although catches of $P$. esculentus were not as strongly influenced by either cycle, catches were higher at night and near low tide.

Several factors affect prawn catchability and activity, and of these, light and tide are the most widely reported influences. Day-night variability in prawn catches is well documented (e.g. Trent 1966, White 1975, Young 1975, Coles 1979) and Staples \& Vance (1979) found a strong tidal periodicity in catches of juvenile Penaeus merguiensis. However, in some field studies (e.g. Clark \& Caillouet 1975, Gamba \& Rodriguez 1987) it has been difficult to decide on the relative importance of tidal and day-night cues in determining observed variations in the abundance of penaeids. Several laboratory studies have shown that penaeids are more active at night (e.g. Hughes 1968, Moller \& Jones 1975, Reynolds \& Casterlin 1979). Fuss 
\& Ogren (1966) reported an inhibitory effect of moonlight on the nocturnal activity of $P$. duorarum, while Minelio et al. (1987) showed that increased turbidity was associated with decreased burying of $P$. aztecus. Tidal rhythms in the direction in which $P$. duorarum swims have been shown by Hughes (1972), while Wickham (1967), Hindley (1975), Subrahmanyan (1976) and Natarajan (1989a, b) found evidence of behavioural responses of several penaeids to daynight and tidal cycles in the laboratory. Prawns became more active as water level or pressure was increased. At constant water levels, prawns showed endogenous tidal cycles, with increased activity near expected high tide. When combined day-night and tidal cycles were observed, less activity occurred at expected day high tides than at night high tides. Temperature (Aldrich et al. 1968, Reynolds \& Casterlin 1979, Hill 1985) and salinity (Hughes 1969, Lakshmi et al. 1976) also influence prawn behaviour and endogenous $24 \mathrm{~h}$ feeding rhythms have been found in laboratory conditions by Hughes (1968) and Kutty \& Murugapoopathy (1968).

Although the main factors associated with catch variation of juvenile penaeids in the Embley River were identified by Vance \& Staples (1992) there was unexplained variation and the patterns of catches in relation to day-night and tidal cycles were not consistent over all sampling periods. This may have been due to environmental variables cycling at different periods (e.g. times of tidal peaks occurred at different times of the day for each sampling period) or modification of cycles by less predictable variables (e.g. daynight effects may have been modified by water turbidity, cloud cover or moonlight). Therefore, the present study examines the responses of juvenile Penaeus esculentus, P. merguiensis and Metapenaeus endeavouri to simulated day-night and tidal cycles imposed separately and simultaneously in controlled laboratory experiments. The relationships between activity responses and the different habitat types used by the 3 species and the effects on field catchability are discussed.

\section{METHODS}

Artificial tide regime. Several studies have shown that penaeid prawns exhibit endogenous tidal cycles without being able to identify the physical factor or factors that entrain the rhythm in the field (e.g. Subrahmanyan 1976). Natarajan (1989b) found that tidal rhythms could be synchronized with artificial cycles of salinity, temperature and water movements and with field variation in hydrostatic pressure but the quickest entrainment occurred with pressure cycles.
Staples \& Vance (1979) found that the strong tidal catchability cycle of juvenile Penaeus merguiensis in an estuary was not noticeably influenced by temperature or salinity and was maintained during the wet season when water was flowing downstream for several weeks, i.e. catches were dependent on tide height rather than current direction. In this study, therefore, cycles of hydrostatic pressure were used to represent the tidal cycle.

In the natural environment used by the prawns in this study, the tidal regime is complex. The tidal period averages $12.4 \mathrm{~h}$ but because of local hydrological and environmental variations, the time between tidal peaks is not the same from day to day. Furthermore, tide heights vary substantially from semi-diumal tides of approximately equal range on the neaps to semidiurnal tides of widely differing ranges or only a diurnal tide on the springs. Because of the large variation in day to day response patterns for individuals and between individuals seen in preliminary experiments and to reduce the complexity of combinations of daynight and tidal cycle stages, I used a constant $12 \mathrm{~h}$ tidal cycle so that the tidal cycle remained in phase with the day-night cycle for each experiment. I also maintained a constant tidal range for all experiments. Systems devised by Graham et al. (1987) and Reid et al. (1989) have enabled much more flexible control of variation in tidal period and tide ranges throughout an experiment and their approach would be valuable for measuring more subtle interactions between tidal and day-night cycles.

Experimental prawns. Juvenile Penaeus esculentus were collected from Moreton Bay, southern Queensland, and $P$. merguiensis and Metapenaeus endeavouri from the Embley River, northern Queensland, using small beam trawls. They were held in a $1000 \mathrm{l}$ outdoor holding tank at the Cleveland Marine Laboratories under a natural day-night cycle in a constant depth of water $(40 \mathrm{~cm})$. Seawater was pumped from about $1 \mathrm{~km}$ offshore into a $120000 \mathrm{l}$ storage tank before circulation to the prawn holding tank to prevent tidal and daynight cycles of salinity and temperature in the water used in experiments. The prawns were held for up to 3 mo prior to experiments and were between 6.0 and $9.9 \mathrm{~mm}$ carapace length (CL) when used in most experiments. To assess the effect of prawn size on the behavioural response, a series of experiments were done with $P$. esculentus of small $(4.0$ to $5.9 \mathrm{~mm} \mathrm{CL})$, medium (6.0 to $9.9 \mathrm{~mm} \mathrm{CL}$ ) and large (10.0 to $12.9 \mathrm{~mm}$ $\mathrm{CL}$ ) sizes. Each prawn was used only once in the series of experiments.

Experimental apparatus and procedure. Prawn activity was monitored individually, using activity chambers and an electronic infrared light system (Fig. 1a). Each activity chamber consisted of a circular channel 

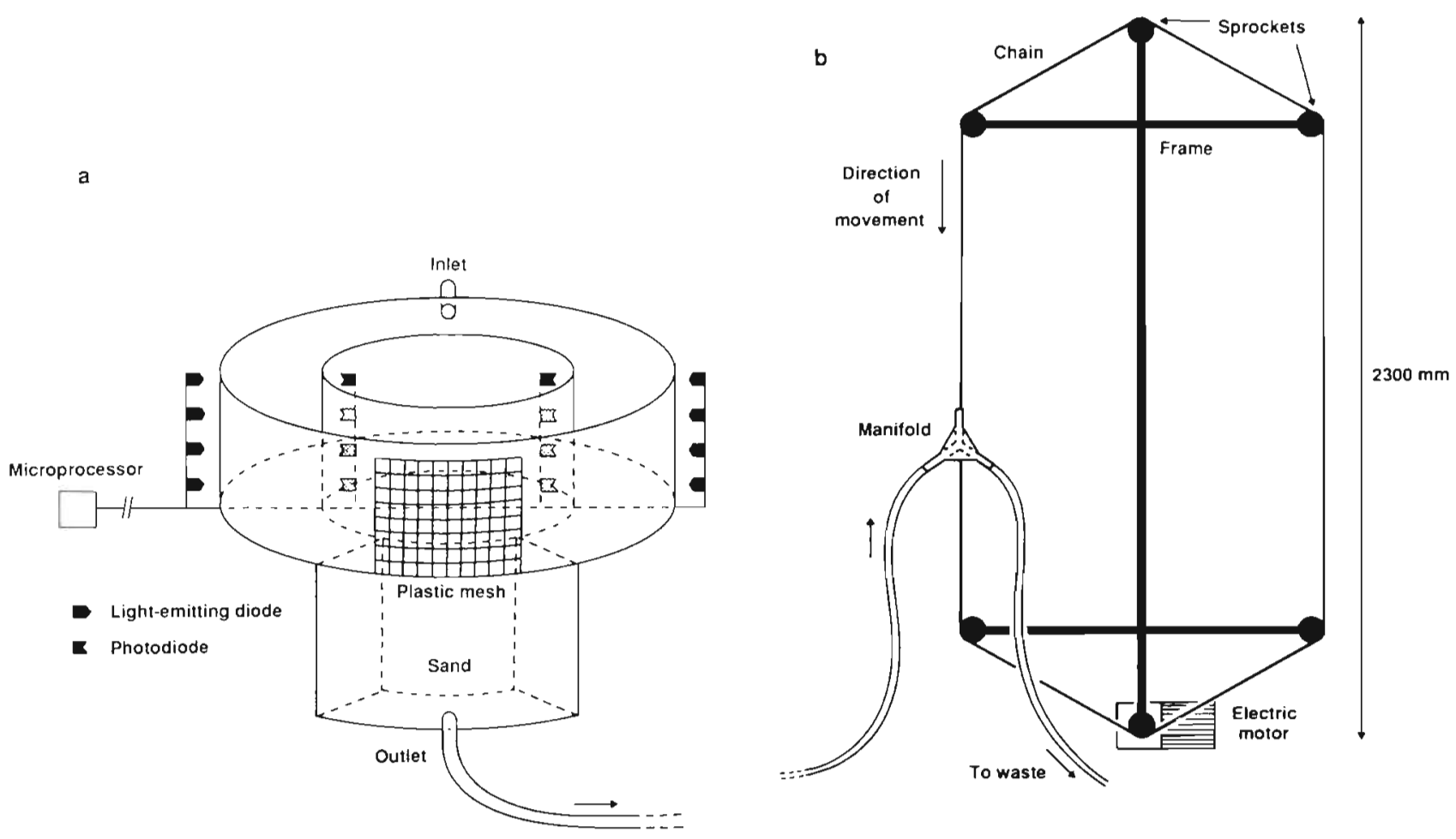

Fig. 1. Schematic diagram of (a) one prawn activity chamber, and (b) apparatus used to create the pressure cycle

constructed from 2 perspex cylinders placed one inside the other such that the diameter of the outer wall of the chamber was $120 \mathrm{~mm}$, the width was $25 \mathrm{~mm}$ and the depth was $30 \mathrm{~mm}$. The chamber had a fixed base and a removable water-tight and pressurized lid. Racek (1959) and Moller \& Jones (1975) found that the rhythmic activity patterns of prawns were influenced by the presence or absence of substrate. Juvenile $P e$ naeus esculentus and Metapenaeus endeavouri are mostly caught in habitats where some vertical structure (seagrass) is abundant (Staples et al. 1985). A segment of the chamber was therefore provided with a marine-sand-filled compartment and plastic mesh to allow the prawns to bury or cling to a vertical structure when they were inactive. Water flowed continuously into the chamber through an inlet near the top and exited diagonally opposite near the bottom of the sand compartment.

The apparatus used to create the pressure cycle was a variation of the tide models which create a sinusoidal change in water level by attaching the end of the outlet pipe from an experimental chamber to an arm rotating in a vertical plane (e.g. Underwood 1972). In this study, the water outflow from all chambers passed through ca $5 \mathrm{~m}$ of high-pressure tubing to a manifold which was open to the atmosphere and then overflowed to waste. The manifold was fixed to a drive chain, and an electric motor, working through 3 reduc- tion gearboxes, drove the chain around a vertical frame, taking $12 \mathrm{~h}$ for 1 revolution (Fig. 1b). This created a cycle of height variation which was similar to the tidal height variation seen in the field. The difference in height between the top and bottom of the frame $(2300 \mathrm{~mm})$ represented the experimental tidal range; spring tide ranges in the areas from which the prawns were collected can reach $2500 \mathrm{~mm}$ while a typical neap tide range is about $1000 \mathrm{~mm}$.

The basic activity recording unit was an array of 4 infrared light-emitting diodes (LEDs) and 4 corresponding photodiodes. The 4 LEDs were placed in a vertical line outside the circular channel and the 4 photodiodes in a parallel line on the inside of the channel so that a prawn moving through the array at any depth interrupted at least one of the beams of infrared light. Each activity chamber was fitted with 2 arrays on opposite sides of the circular chamber (Fig. 1a) and a prawn movement across either array was registered by a microprocessor. The microprocessor accumulated activity counts from up to 5 separate chambers continuously and output the individual totals to a printer at predetermined intervals (usually $30 \mathrm{~min}$ ).

Prawns of each species were tested under 4 experimental regimes (Table 1). Each factor was tested with the other held constant (Regimes 1 and 2). To assess the effects of interactions of the 2 factors on prawn activity, 2 combinations of the factors were tested, with 
Table 1. Experimental regimes used to assess activity responses of juvenile Penaeus esculentus (PE), P. merguiensis (PM) and Metapenaeus endeavouri (ME) to day-night and tidal cycles

\begin{tabular}{|c|c|c|c|c|c|}
\hline Regime & Light on & Light off & Low tide & High tide & Species tested \\
\hline 1 & \multicolumn{2}{|c|}{ Constant dark } & $09: 00 / 21: 00 \mathrm{~h}$ & $03: 00 / 15: 00 \mathrm{~h}$ & $P E, P M, M E$ \\
\hline 2 & $06: 00 \mathrm{~h}$ & $18: 00 \mathrm{~h}$ & \multicolumn{2}{|c|}{ Constant low tide } & PE, PM, ME \\
\hline 3 & $06: 00 \mathrm{~h}$ & $18: 00 \mathrm{~h}$ & $09: 00 / 21: 00 \mathrm{~h}$ & $03: 00 / 15: 00 \mathrm{~h}$ & PE, PM, ME \\
\hline 4 & $06: 00 \mathrm{~h}$ & $18: 00 \mathrm{~h}$ & 03:00/15:00 h & $09: 00 / 21: 00 \mathrm{~h}$ & $P E, P M, M E$ \\
\hline 5 & \multicolumn{2}{|c|}{ Constant light } & 09:00/21:00 h & $03: 00 / 15: 00 \mathrm{~h}$ & $\mathrm{PE}$ \\
\hline 6 & \multicolumn{2}{|c|}{ Constant light } & 03:00/15:00 h & $09: 00 / 21: 00 \mathrm{~h}$ & $\mathrm{PE}$ \\
\hline
\end{tabular}

the tide cycle advanced by $6 \mathrm{~h}$ in one case (Regimes 3 and 4). In addition, Penaeus esculentus was tested under another 2 experimental regimes in which prawns were held under constant light (Regimes 5 and 6 ). Between 7 and 18 prawns were used and between 28 and 8824 h activity periods were recorded for each experimental regime.

No attempt was made to synchronize the timing of the laboratory tidal cycle with the timing of tides in the field at time of capture. Lighting was provided by 2 white $40 \mathrm{~W}$ fluorescent tubes that were switched on and off by a timer. Light intensity when the lights were on was ca $1.8 \mu \mathrm{E} \mathrm{m}^{-2} \mathrm{~s}^{-1}$. Temperature in the prawn chambers was maintained between 28 and $30^{\circ} \mathrm{C}$. Salinity varied from 30 to $37 \mathrm{ppt}$ over all experiments and in any one experiment salinity varied by less than 2 ppt. This variation was a result of rainfall runoff, and was not synchronized with the natural tidal cycle.

In all experiments prawns were placed in individual acclimation chambers (similar in size to the activity chambers but without the electronics) 6 to $7 \mathrm{~d}$ before being placed into the activity chambers. The appropriate day-night and tidal regime was maintained in both the acclimation and test chambers. Activity was then recorded for 5 to $7 \mathrm{~d}$ in most cases. Prawns were fed at 12:00 h each day through an inlet line with a pressure lock to maintain the pressure cycle in the chambers. Hughes (1968) and Kutty \& Murugapoopathy (1968) found that, by feeding Penaeus duorarum and $P$. semisulcatus, respectively, at the same time each day, $24 \mathrm{~h}$ activity rhythms could sometimes be induced with increased activity at the time of feeding. By feeding at 12:00 h each day in this study I hoped that any induced feeding rhythm would be identified as such and the activity resulting from feeding would be, to a certain extent, separate from activity changes due to day-night and tidal cycles. The chambers were not opened during an experiment but were inspected at least once a. day to assess the health of the prawns and functioning of the apparatus. During constant-dark experiments a redfiltered torch was used for the short daily checks.

Analyses of activity. For all experiments, activity counts were summed over $1 \mathrm{~h}$ periods. Initial inspec- tion and analysis of the results for individual prawns showed large variation between individuals and for individuals from day to day. Activity was, therefore, standardized across individuals by expressing each prawn's hourly activity as a proportion of the maximum hourly activity measured for that prawn over the $24 \mathrm{~h}$ period. The proportional data were then transformed using the arcsine of the square root of each proportion (Snedecor \& Cochran 1978). Because several individuals were measured simultaneously (up to 5 per experimental run) a further mean was calculated for all individuals for each experimental run and these means were used in further analyses. Hourly mean activity counts were analysed with the General Linear Models procedure of the SAS statistical package (SAS Institute Inc. 1988). One-way analysis of covariance was used with day-night as the class variable and tide height as the continuous variable, and a more complex 2-way analysis of covariance used day-night and experimental regime as the class variables. Other continuous variables used in the 2-way analysis were: a day-night switch variable (which took the value -1 for the first $4 \mathrm{~h}$ of light,+1 for the first $4 \mathrm{~h}$ of dark and 0 for all other times); tide lagged by $1 h_{i}$ and the previous hour's activity count.

The significance of the day-night cycle was more rigorously tested by calculating a single mean activity for each day and night period for each individual and then calculating a further mean value for each experimental run. The experimental run means were used in an analysis of variance with day-night as the class variable.

Figures of activity patterns were drawn using untransformed data. Activity was standardized across individuals by expressing each prawn's hourly activity as a percentage of the maximum hourly activity measured for that prawn over the $24 \mathrm{~h}$ period. Means of the hourly percent activities of all prawns and combined for all days for each experimental regime were then used for the figures but because several individuals were measured simultaneously (up to 5 per experimental run) the number of experimental runs was used as the sample size for calculating standard errors. 


\section{RESULTS}

\section{Penaeus esculentus}

In all experiments where hydrostatic pressure was varied, medium-sized Penaeus esculentus became more active around high tide (when hydrostatic pressure was highest), with peaks 1 to $2 \mathrm{~h}$ after high tide (Figs. 2a, c, d \& 3a,b). The lowest activity periods were around or just after the times when pressure was lowest ('low tide'). When prawns were exposed to a day-night cycle (Fig. 2b, c, d), either with or without a tidal cycle, they were more active during the dark periods.

Under constant dark conditions and with a simulated tidal cycle imposed (Fig. 2a), peaks of approximately equal height were observed just after each high tide. Activity then decreased quickly, was lowest around or just after low tide, and increased more gradually as the tide rose. Prawns held under constant light also showed activity peaks of approximately equal height just after high tide, irrespective of the time of high tide (Fig. 3a, b). However the levels of maximum activity were lower under constant light conditions (about 100 counts $\mathrm{h}^{-1}$ ) than constant dark (about 240 counts $\mathrm{h}^{-1}$ ).

In the absence of a tidal cycle (constant low tide; Fig. 2b) overall activity levels were higher at night than during the day. Activity was lowest in the first $4 \mathrm{~h}$ after the lights were switched on, increased throughout the rest of the day and then increased sharply after dark. Peak activity was in the second hour after dark and decreased gradually throughout the night

When tidal and day-night cycles were imposed simultaneously with high tide at 03:00 and 15:00 h (Fig. 2c) activity again peaked just after high tide, but the night peak was higher than the day peak. Similarly when the tidal cycle was shifted by 6 h relative to the day-night cycle so that high tide was at 09:00 and 21:00 h (Fig. 2d) the night high-tide activity peak was nearly twice the day peak. However, when high tide occurred early in the night period the high-tide activity level was almost twice that when high tide occurred late in the night period.

In some experiments activity increased around 12:00 $\mathrm{h}$, which may be associated with the introduction of food to the chambers (Figs. 2b, c \& 3a). Prawns were often seen to arouse from an apparently resting state and begin feeding within 5 min of food being added. A small increase in activity 1 to $2 \mathrm{~h}$ before the lights were switched on is also apparent in some experiments (Fig. 2b, d)

Rhythms of prawn activity were clearly influenced by both day-night and tide cycles (Fig. 2). A simple
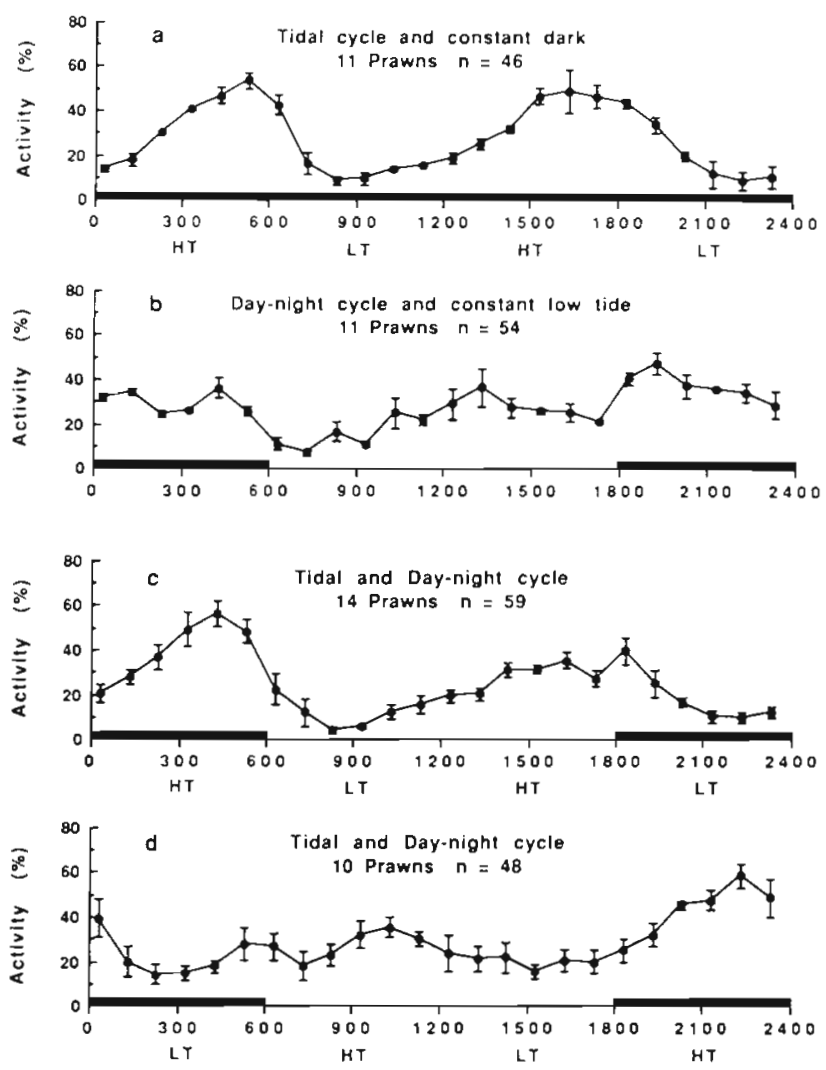

Fig. 2. Penaeus esculentus. Mean percent activity (see 'Methods') of medium-sized prawns (6.0 to $9.9 \mathrm{~mm} \mathrm{CL})$ throughout a $24 \mathrm{~h}$ period for (a to d) Regimes 1 to 4 (Table 1). Vertical bars: standard errors; horizontal bars: hours of darkness; HT: high tide; LT: low tide; n: no. of 24 h records
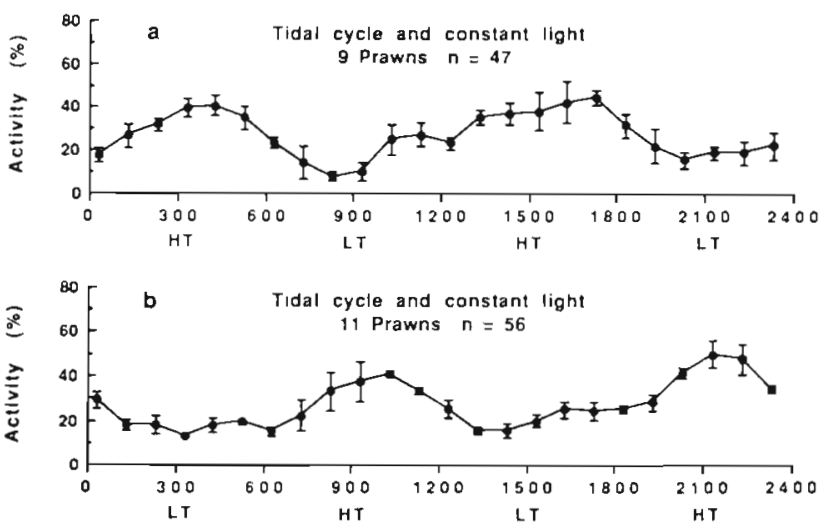

Fig. 3. Penaeus esculentus. As in Fig. 2 but (a) Regime 5 and (b) Regime 6

analysis of variance using only day-night and using a single estimate for day and night activity for each experimental run was carried out on data from the first 4 experimental regimes. Day-night was highly significant and explained $35.8 \%$ of the variation in activity (Table 2a). In an analysis of covariance using hourly 
Table 2. Penaeus esculentus. Analysis of covariance of arcsine-transformed activity counts of juveniles with (a) day-night, (b) day-night and tide height, and (c) day-night, day-night switch, tide height lagged by $1 \mathrm{~h}$, previous hour's activity and experimental regime df: degrees of freedom; SS: sums of squares; \% variation: percentage of the total activity variation explained by each variable

\begin{tabular}{|c|c|c|c|c|c|}
\hline & Source of variation & df & SS & $F$-ratio & $\%$ Variation \\
\hline \multirow[t]{2}{*}{ (a) } & Day-night & 1 & 0.073 & $17.90^{\cdots} \cdot$ & 35.8 \\
\hline & Error & 32 & 0.131 & & \\
\hline \multirow[t]{4}{*}{ (b) } & Day-night & 1 & 1.019 & $46.45 \cdots$ & 10.4 \\
\hline & Tide height & 1 & 1.976 & $90.07 \cdots$ & 20.1 \\
\hline & Day-night $\times$ Tide height & 1 & 0.062 & 2.82 & 0.6 \\
\hline & Error & 308 & 6.756 & & \\
\hline \multirow[t]{6}{*}{ (c) } & Day-night & 1 & 1.019 & $98.00 \cdots$ & 10.4 \\
\hline & Day-night switch & 1 & 0.435 & $41.82 \cdots$ & 4.4 \\
\hline & Tide height lagged & 1 & 2.625 & $252.46^{\cdots}$ & 26.7 \\
\hline & Previous activity & 1 & 2.069 & $199.01 \cdots$ & 21.1 \\
\hline & Experimental regime & 3 & 0.505 & $16.18 \cdots$ & 5.1 \\
\hline & Error & 304 & 3.161 & & \\
\hline$\cdots p$ & & & & & \\
\hline
\end{tabular}

estimates of activity and using day-night and tide height, light accounted for $10.4 \%$ of the hourly variation in activity, while tide height explained $20.1 \%$ (Table 2b). There was no significant interaction between tide and light.

Further statistical analysis was undertaken to look at factors more subtle than simply tide height and daynight levels. The importance of the switch between day and night phases, the rising compared to the falling stage of the tide, and a lagged response to tide height were tested by analysis of covariance. Daynight, a day-night switch variable, tide with a high-tide lag of $1 \mathrm{~h}$, the previous hour's activity and the experiment number were all highly significant $(p<0.001)$ in a model that explained $67.7 \%$ of the variation in activity (Table 2c).

Size effects. The effect of prawn size was assessed with a single experimental regime incorporating a day-night and tidal cycle with high tides at 03:00 and 15:00 h. All the size groups seemed to react to the day-night and tide cycles in a similar way, but the relative strength of the reactions was different for each group (Fig. 4). The response to day-night was very strong in the small prawns, while tide seemed to be less important; the peak of activity near the day high tide was almost negligible. With increasing size, the day-night effect decreased and the tidal response became more pronounced. In the largest prawns a day-night response was only noticeable in the slight increase in activity just after lights off and the trough in activity just after lights on. The highest activity was late in the day around high tide.
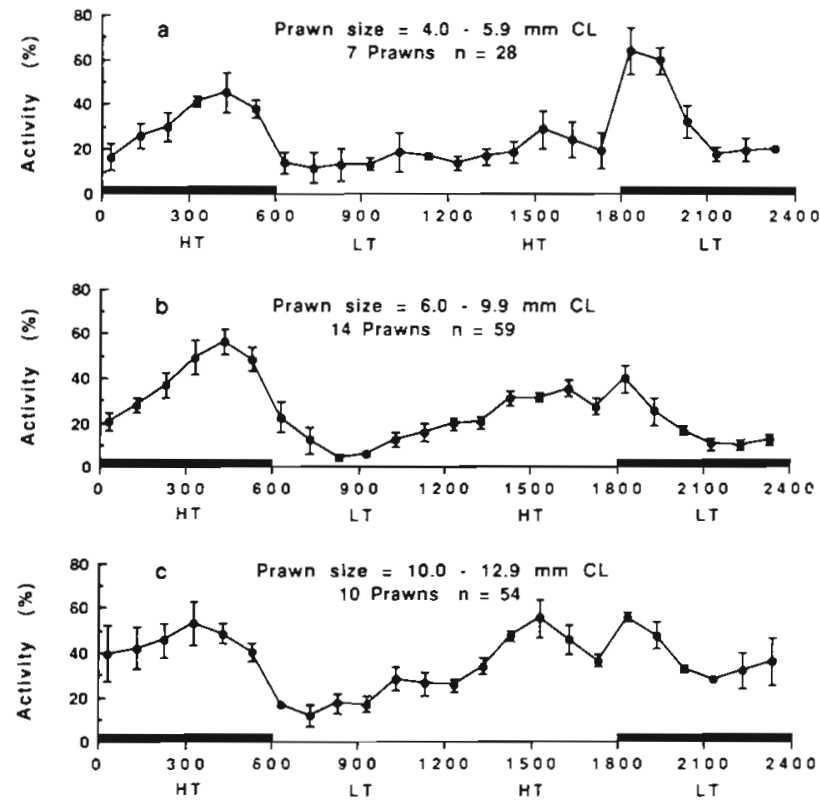

Fig. 4. Penaeus esculentus. Mean percent activity (see 'Methods') of 3 size groups of prawns throughout a 24 h. period for Regime 3 (Table 1). Symbols and abbreviations as in Fig. 2

\section{Penaeus merguiensis}

In all experiments where tide height was varied, activity was mostly high around or just after high tide (Fig. Sa, c, d). When a day-night cycle was imposed, either with or without a tidal cycle, prawns were more active at night (Fig, 5b, c, d). Under constant dark and with a tidal cycle imposed, activity 

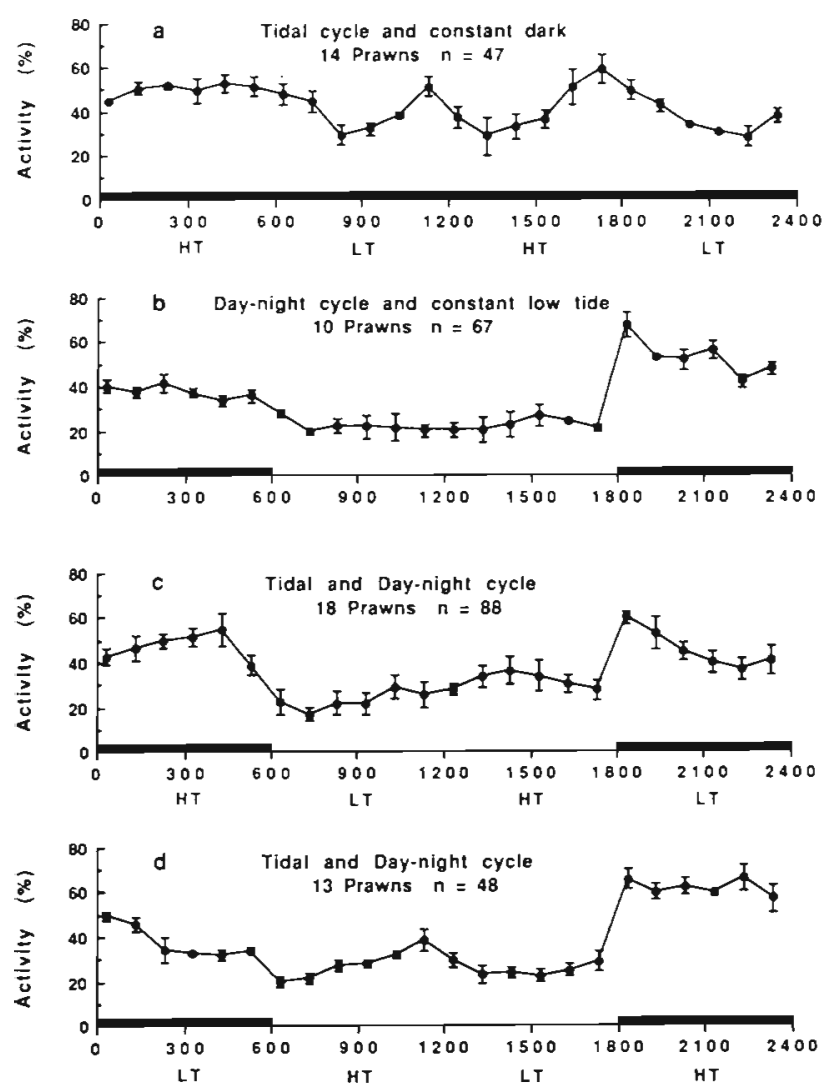

Fig. 5. As in Fig. 2 but for Penaeus merguiensis

was high just after high tide and lowest near low tide, although there was also a peak just before 12:00 h (Fig. 5a). With no tidal cycle (constant low tide; Fig. 5b) activity increased sharply after dark, remained high for $4 \mathrm{~h}$, and then decreased gradually throughout the night. Activity remained low throughout the day.
When tidal and day-night cycles were imposed simultaneously, activity again increased sharply when the lights were switched off (Fig. 5c, d). When high tide occurred at 03:00 and 15:00 h, activity peaked just after or just before high tide but the night peak was higher than the day peak (Fig. 5c). When high tide was at 09:00 and 21:00 h, the night activity peak was twice the day peak.

In general, Penaeus merguiensis seemed to be more active than $P$. esculentus: the peaks of activity were no higher but the lowest activity levels were not as low in most experiments except when the tide height was constant (Fig. 2b). As with $P$. esculentus, there is a suggestion of a feeding activity peak just before 12:00 h in some experiments (Fig. 5a,d) and a pre-dawn increase in activity (Fig. 5b, d).

An analysis of variance using day-night alone was highly significant and explained $70.0 \%$ of the variation in activity (Table $3 a$ ). In an analysis of covariance using tide and day-night as variables and using hourly estimates of activity, $42.5 \%$ of the activity variation was explained by day-night and $7.3 \%$ by tide (Table $3 \mathrm{~b}$ ). Further analysis of covariance with a more complex model using the same variables as for Penaeus esculentus explained $67.9 \%$ of the variation in activity (Table 3c).

\section{Metapenaeus endeavouri}

When subjected to a tidal cycle under constant dark Metapenaeus endeavouri showed peaks of activity around and just after high tide (Fig. 6a). The activity peak associated with the 15:00 h high tide is slightly later than the 03:00 h high-tide peak and also extends for longer. When prawns were kept at constant low tide (Fig. 6b), almost no activity occurred during the

Table 3 . As in Table 2 but for Penaeus merguiensis

\begin{tabular}{|c|c|c|c|c|c|}
\hline & Source of variation & df & SS & F-ratio & $\%$ Variation \\
\hline \multirow[t]{2}{*}{ (a) } & Day-night & 1 & 0.296 & $46.58 \cdots$ & 70.0 \\
\hline & Error & 20 & 0.127 & & \\
\hline \multirow[t]{4}{*}{ (b) } & Day-night & 1 & 3.667 & $281.02 \cdots$ & 42.5 \\
\hline & Tide height & 1 & 0.627 & $48.03 \cdots$ & 7.3 \\
\hline & Day-night $\times$ Tide height & 1 & 0.001 & 0.05 & 0.0 \\
\hline & Error & 332 & 4.332 & & \\
\hline \multirow[t]{6}{*}{ (c) } & Day-night & 1 & 3.667 & $434.83 \cdots$ & 42.5 \\
\hline & Day-night switch & $i$ & 0.540 & $64.08 \cdots$ & 6.3 \\
\hline & Tide height lagged & 1 & 0.674 & $79.94 \cdots$ & 7.8 \\
\hline & Previous activity & 1 & 0.959 & $113.72 \cdots$ & 11.1 \\
\hline & Experimental regime & 3 & 0.020 & 0.79 & 0.2 \\
\hline & Error & 328 & 2.766 & & \\
\hline$\cdots_{p}$ & & & & & \\
\hline
\end{tabular}



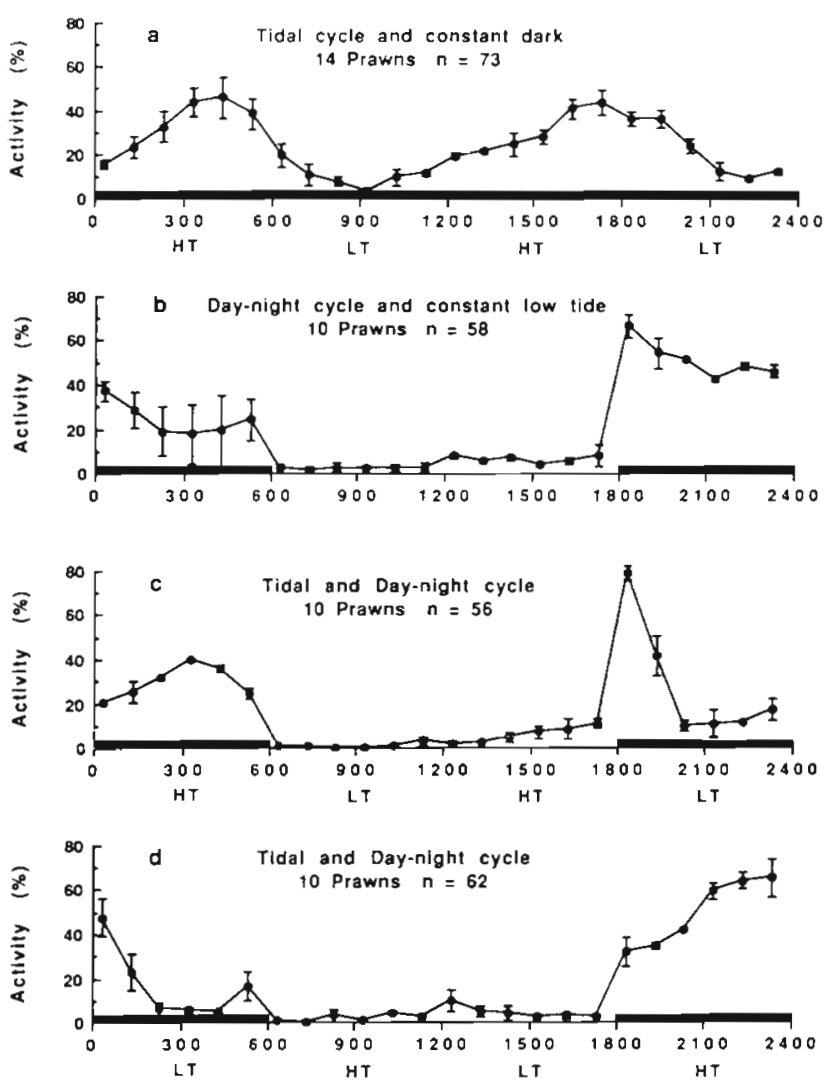

Fig. 6. As in Fig. 2 but for Metapenaeus endeavouri

day $_{i}$ most prawns were buried in the substrate. Activity increased immediately after dark, remained high until just before midnight and then gradually declined through the rest of the night, dropping to zero immediately after lights on.
When day-night and tide cycles were imposed together, virtually no activity occurred during daylight hours. However the night activity was modified substantially by the tide height, with activity dropping to zero around low tide (Fig. 6c, d). The slight rise in activity at 12:00 $\mathrm{h}$ in all experiments was associated with the time of feeding, and in some experiments there is a pre-dawn increase in activity (Fig. 6b, d).

Metapenaeus endeavouri responded to day-night and tide in a similar manner to the other species, but the strength of the day-night effect far outweighed the tidal effect when both cycles were imposed. Day-night alone in an analysis of variance explained $94.3 \%$ of the variation in activity (Table 4a). When day-night and tide were considered in the analysis using hourly estimates of activity, $44.2 \%$ of activity variation was explained by day-night and only $4.8 \%$ by tide height (Table $4 \mathrm{~b}$ ). There was also a small but significant interaction between day-night and tide due to the almost complete lack of activity of $M$. endeavouri during the day high tide compared to the night high tide. (This interaction was not significant for Penaeus esculentus or $P$. merguiensis.) Although day-night was the strongest influence on activity, in the experiment where tide height alone was varied, tide height explained $46 \%$ of the variation in activity $(\mathrm{p}<0.001$; Fig. 6a). A more complex analysis of covariance model explained $80.6 \%$ of the total activity variation (Table 4c).

\section{Comparison of activity levels}

Comparison of activity levels between experiments and between species must be treated with caution as

Table 4. As in Table 2 but for Metapenaeus endeavouri

\begin{tabular}{|c|c|c|c|c|c|}
\hline & Source of variation & $\mathrm{df}$ & SS & F-ratio & $\%$ Variation \\
\hline \multirow[t]{2}{*}{ (a) } & Day-night & 1 & 0.504 & $164.97 \cdots$ & 94.3 \\
\hline & Error & 10 & 0.031 & & \\
\hline \multirow[t]{4}{*}{ (b) } & Day-night & 1 & 5.853 & $193.10 \cdots$ & 44.2 \\
\hline & Tide height & 1 & 0.638 & $21.05 \cdots$ & 4.8 \\
\hline & Day-night $\times$ Tide height & 1 & 0.325 & $10.71 \cdots$ & 2.5 \\
\hline & Error & 212 & 6.426 & & \\
\hline \multirow[t]{7}{*}{ (c) } & Day-night & 1 & 5.853 & $468.04 \cdots$ & 44.2 \\
\hline & Day-night switch & 1 & 0.935 & $74.73 \cdots$ & 7.1 \\
\hline & Tide height lagged & 1 & 1.208 & $96.56 \cdots$ & 9.1 \\
\hline & Day-night $\times$ Tide lagged & 1 & 0.485 & $38.80^{\cdots} \cdots$ & 3.7 \\
\hline & Previous activity & 1 & 1.609 & $128.67^{\cdots} \cdot$ & 12.2 \\
\hline & Experimental regime & 3 & 0.563 & $15.02 \cdots$ & 4.3 \\
\hline & Error & 207 & 2.589 & & \\
\hline \multicolumn{6}{|c|}{$\because p<0.001$} \\
\hline
\end{tabular}


Table 5. Penaeus esculentus, P. merguiensis and Metapenaeus endeavouri. Mean and maximum activity levels (counts $\mathrm{h}^{-1}$ ) for each experimental regime. SE: standard error; Max: maximum

\begin{tabular}{|c|c|c|c|c|c|c|c|}
\hline \multicolumn{2}{|c|}{ Experimental regime } & \multicolumn{2}{|c|}{ P. esculentus } & \multicolumn{2}{|c|}{ P. merguiensis } & \multicolumn{2}{|c|}{ M. endeavouri } \\
\hline & & Mean \pm SE & Max & Mean $\pm S E$ & $\operatorname{Max}$ & Mean \pm SE & $\operatorname{Max}$ \\
\hline 1. & $\begin{array}{l}\text { Constant dark } \\
\text { High tide: 03:00/15:00 h }\end{array}$ & $117.7 \pm 4.5$ & 240 & $151.8 \pm 3.8$ & 220 & $80.6 \pm 3.8$ & 182 \\
\hline 2. & $\begin{array}{l}\text { Day-night cycle } \\
\text { Constant low tide }\end{array}$ & $67.1 \pm 2.8$ & 149 & $68.0 \pm 2.3$ & 147 & $77.7 \pm 4.3$ & 204 \\
\hline 3. & $\begin{array}{l}\text { Day-night cycle } \\
\text { High tide: 03:00/15:00 h }\end{array}$ & $53.9 \pm 2.0$ & 122 & $111.9 \pm 3.0$ & 202 & $39.1 \pm 2.7$ & 206 \\
\hline 4. & $\begin{array}{l}\text { Day-night cycle } \\
\text { High tide: } 09: 00 / 21: 00 \mathrm{~h}\end{array}$ & $85.9 \pm 3.5$ & 211 & $134.1 \pm 3.7$ & 253 & $54.6 \pm 3.7$ & 242 \\
\hline 5. & $\begin{array}{l}\text { Constant light } \\
\text { High tide: 03:00/15:00 h }\end{array}$ & $34.4 \pm 1.7$ & 62 & & & & \\
\hline & $\begin{array}{l}\text { Constant light } \\
\text { High tide: 09:00/21:00 h }\end{array}$ & $49.0 \pm 1.8$ & 97 & & & & \\
\hline
\end{tabular}

the experiments were carried out over several years and the prawns were collected from different locations and times of the year. Nevertheless some trends are apparent.

For experimental Regimes 1, 3 and 4, Penaeus merguiensis had the highest mean activity level and Metapenaeus endeavouri the lowest (Table 5). The ranking of these means is driven largely by the activity levels of each species in periods when activity is low; the highest activity level recorded for each species is very similar ( 240 to 253 counts $h^{-1}$ ). $M$. endeavouri activity levels are zero when in an inactive mode, the lowest activity levels of $P$. esculentus are slightly higher, and the lowest activity levels of $P$. merguiensis are relatively high. For every species, the highest mean activity level occurred under conditions of constant dark (Table 5). All species also registered a very high peak of activity when high tide was at 21:00 h (Regime 4); high tide and the first period of the night seemed to have an additive effect on activity levels (Figs. $2 d, 5 d \& 6 d$ ).

\section{DISCUSSION}

\section{Day-night activity}

The results of this study have shown that when exposed to the artificial day-night cycle only, all 3 species of prawns were more active at night. Metapenaeus endeavouri was most clearly affected: virtually no activity occurred during the day. Penaeus merguiensis was less strongly affected: low levels of activity occurred during the day, while the activity of $P$. esculentus var- ied least between day and night. Furthermore, peak activity of all species was in the first half of the night period: for $P$. esculentus, activity was greatest in the second hour after dark, whereas for $P$. merguiensis and $M$. endeavouri, activity remained high for 4 and $7 \mathrm{~h}$ after dark, respectively, before decreasing. The activity levels of $P$. esculentus and $M$. endeavouri remained at their lowest levels for the first 4 and $6 \mathrm{~h}$ of daylight, respectively, and then increased throughout the remainder of the day. P. merguiensis showed no consistent change in activity levels during the day. These results are consistent with reports of many other researchers who have shown that prawns are more active at night (e.g. Hindley 1975, Moller \& Jones 1975 , Reynolds \& Casterlin 1979).

\section{Tidal activity}

When a tidal cycle was imposed under constant $24 \mathrm{~h}$ light, the activity of all species increased as the tide height increased, with the prawns being most active 2 to $3 \mathrm{~h}$ after high tide. The lowest activity levels were within an hour of the time of low tide. Several other studies have recorded endogenous tidal rhythms of activity of penaeid prawns, with peaks near the time of expected high tide (e.g. Subrahmanyan 1976. Natarajan 1989a). Wickham (1967) found that juvenile Penaeus duorarum in the laboratory became more active when the water level was raised, but Hindley (1975) found no similar change with juvenile $P$. merguiensis. However, his pressure changes were sudden and did not simulate the gradual changes of a tidal cycle. 


\section{Day-night and tidal activity}

Although Wickham (1967), Hindley (1975), Subrahmanyan (1976) and Natarajan (1989a, b) have observed interactions between day-night cycles and endogenous tidal rhythms, no studies have recorded the activity responses of penaeids to simulated daynight and tidal cycles together and therefore the relative importance of each factor in influencing behaviour patterns. In the present study, when tide and day-night cycles were superimposed, both factors clearly contributed to the overall activity patterns observed. In all species, highest activity levels were at night and peaks occurred either in the first $2 \mathrm{~h}$ of the night period or in the 2 to $3 \mathrm{~h}$ after high tide at night. For all species, activity was highest when high tide was in the first half of the night period. However, the relative strengths of the responses to tide and day. night were different for each species. The day-night cycle was the dominant influence on Metapenaeus endeavouri: virtually no activity occurred during the day regardless of the tide height. Penaeus merguiensis and $P$. esculentus were less influenced by the daynight cycle and were active during the day as well as night; however, the difference in activity between daytime high and low tides was greater for $P$. esculentus than for $P$. merguiensis.

These experiments were not designed to assess endogenous cycles of activity; the acclimation period was expected to remove the affects of any endogenous activity rhythms associated with the prawns' previous environment. However, it appears that in some experiments the prawns' behaviour was influenced by an endogenous rhythm associated with the day-night cycle. For example, for Penaeus esculentus (Fig. 2a) and for Metapenaeus endeavouri (Fig. 6a), under conditions of constant dark, the late afternoon peak of activity just after high tide was extended, compared to the early morning peak, and activity remained high for the first $2 \mathrm{~h}$ of expected night time. Also in all the experiments where activity was seen to be relatively low in the last half of the night, a small rise in activity was seen at 04:00 to 05:00 $\mathrm{h}$, before the decrease in activity associated with the onset of daylight. This suggests that the prawns were anticipating the end of the night period. However, there was no sign of a pre-dusk rise in activity, which has been reported by Reynolds \& Casterlin (1979) for juvenile P. duorarum.

\section{Comparisons with field catchability}

Vance \& Staples (1992) have discussed in detail the significance of these results in relation to trawl catches of the 3 species in the field. All 3 species were more catchable at night and the relative catchabilities with respect to day-night were very similar to the laboratory changes in activity. Metapenaeus endeavouri were virtually only caught at night whereas Penaeus esculentus and $P$. merguiensis were also caught during the day. It was suggested that prawns are more catchable at night because they are less able to detect and therefore avoid the net, and in the case of $P$. esculentus and $M$. endeavouri, they have emerged from the substrate. Catches of all species were lowest at high tide. P. merguiensis were least catchable because they entered the mangrove forests at high tide where trawling was not possible. P. esculentus and $M$. endeavouri may have been able to avoid the net when they were more active near high tide but also may have been swimming in the water column above the path of the net. As the water level dropped, all species became more concentrated in the water column and possibly tended to settle to the bottom as their activity decreased; their catchability by the beam trawl increased. $P$. esculentus and $M$. endeavouri remain on the seagrass flats at low tide and bury in the substrate and catches are therefore very low at this time (CSIRO Division of Fisheries, unpubl. data). P. merguiensis, however, do not bury at low tide but follow the water level down on each tide cycle. They are concentrated close to the water's edge and are, therefore, more catchable to a beam trawl at this time.

\section{Comparisons of activity levels}

The lowest activity levels of Penaeus merguiensis under all laboratory conditions were considerably higher than the lowest levels for $P$. esculentus or Metapenaeus endeavouri; this is probably related to the habitat utilized by each species. $P$. merguiensis inhabits mangrove-lined small creeks and rivers with steeply sloping mud banks and moves large distances during a tidal cycle as the water level changes (Vance et al. 1990). Towards low tide they aggregate in the very shallow turbid water close to the river edge, which presumably affords them protection from predation. Because the tidal currents in this habitat are often strong, some activity is probably required to maintain position close to the water's edge. In contrast, $P$. esculentus and $M$. endeavouri mainly inhabit wide seagrass flats (Staples et al. 1985) where the tidal currents are not as strong and where they can avoid or reduce predation by burying in the substrate or by remaining motionless amongst or on the seagrass. Therefore the lowest activity levels for these 2 species would be virtually zero. 


\section{Effect of size}

The variation in response to day-night and tide with size of Penaeus esculentus is difficult to interpret. Because only 1 combination of day-night and tide was tested, the results were not as definite as for the comparisons among species. However, it appears that the day-night cycle was most important in determining the small prawns' activity while the tidal cycle was more important for the larger prawns. It is unlikely that the change is related to immigration or settlement behaviour as the smallest prawns tested would have been settled on the seagrass beds for about 2 wk when collected.

The difference may be related to feeding behaviour of the prawns. A recent study on the diet of juvenile Penaeus esculentus (C. J. O'Brien pers. comm.) showed that postlarval and small juvenile prawns mainly ate diatoms and filamentous algae but as the prawns increased in size they used less vegetation and more live animal matter in their diet. The larger prawns, therefore, probably have to forage over a far greater area to find the diverse food items which comprise their diet. The intertidal nature of the seagrass beds would make it extremely difficult for larger prawns to forage at low tide whereas smaller prawns could still be active in the 2 to $5 \mathrm{~cm}$ deep pools which are left at low tide. The reason is still uncertain and more detailed studies on the feeding behaviour, area of foraging and use of the seagrass itself are needed.

\section{Activity patterns and habitat}

The activity patterns of juvenile prawns resident in an estuarine environment are probably influenced by 2 main factors: the need to have regular access to food sources and to gain protection from predators. Although the 3 species studied in these experiments usually utilize 2 distinct habitat types, the use of each habitat is similar in relation to the tidal cycle. The seagrass beds used by Penaeus esculentus and Metapenaeus endeavouri are often exposed at low tide, when the prawns are almost certainly buried in the substrate: they are not found in deeper water adjacent to the seagrass at low tide. It is, therefore, often only possible for the prawns to forage for food on the higher tide levels. Wading birds, which are significant predators of shrimp on seagrass beds in other areas (e.g. Howard \& Lowe 1984) and on penaeid prawns in estuaries (Mukherjee 1971), fish in shallow water. Therefore it would be advantageous to the prawns to feed near high tide and avoid predation either by burying in the substrate or hiding amongst the seagrass near low tide. Also on spring low tides, when the sea- grass is exposed, the prawns would bury to avoid desiccation. Similarly, for $P$. merguiensis, the mangrove forests in which juvenile $P$. merguiensis feed are only inundated towards high tide (T. J. Wassenberg \& B. J. Hill, CSIRO Division of Fisheries, unpubl. data). Less feeding appears to take place near low tide, when the prawns tend to aggregate in the very shallow turbid water close to the banks rather than burying in the substrate

All 3 species of prawns are eaten by several species of fish in the Embley River (Salini et al. 1990). Although some of the fish feed at night, many feed primarily in the day and so decreased prawn activity during the day would probably decrease the chances of predation by fish and birds. Penaeus esculentus was least affected by the day-night cycle but its colouration (brown and green bands and patches) would help it to merge with the seagrass. This colouration and close association with seagrass may give $P$. esculentus more protection from predation during the day than the other species.

Studies on several other penaeid species from Australia (Racek 1959), North America (e.g. Fuss \& Ogren 1966, Hughes 1968, Reynolds \& Casterlin 1979), India (Kutty \& Murugapoopathy 1968, Natarajan 1989a) and Venezuela (Gamba \& Rodriguez 1987) have all shown that penaeids are most active at night. A few studies have also shown that penaeids were more active under increased water pressure or showed endogenous cycles of increased activity near the times of expected high tide. In one of the few studies to consider both tidal and day-night cycles, Subrahmanyan (1976) suggested that an endogenous day-night rhythm was a stronger influence on the overall activity pattern of Penaeus duorarum than was an endogenous tidal rhythm. This result is similar to what we observed for Metapenaeus endeavouri. Juvenile P. duorarum are found in similar vegetated habitat, have similar patterns of colouring and probably utilize the habitat in a similar way.

All the penaeid species examined in this and other studies have been shown to respond similarly to tidal and day-night cycles: in general, they are more active near high tide when food sources would be accessible to them, and also more active at night when the risk of predation is less. For the species in the present study, the adaptive significance of these similar responses is clear although the habitats utilized by the prawns are different.

Acknowledgements. I thank Dr D. Staples of the CSIRO Division of Fisheries Research, Marine Laboratories, Cleveland, for helpful advice and assistance at all stages of this study. Mr R. Stokes, formerly of the CSIRO Electronics Section, Marine Laboratories, Hobart, designed and constructed much 
of the electronic apparatus. Mr J. Cordell and Mr M. Sherlock of the above laboratories helped maintain the electronics. Mr $\mathrm{J}$. Kerr of the CSIRO Biometrics Unit, Long Pocket Laboratories, provided much good advice on the statistical analyses. Drs B. Hill and P. Rothlisberg of CSIRO Marine Laboratories, Cleveland, constructively criticised the manuscript.

\section{LITERATURE CITED}

Aldrich, D. V., Wood, C. E., Baxter, K. N. (1968). An ecological interpretation of low temperature responses in Penaeus aztecus and $P$. setiferus postlarvae. Bull. mar. Sci. 18: $61-71$

Clark, S. H., Caillouet, C. W. (1975). Diel fluctuations in catches of juvenile brown and white shrimp in a Texas estuarine canal. Contr. mar. Sci. 19: 119-124

Coles, R. G. (1979). Catch size and behaviour of pre-adults of three species of penaeid prawns as influenced by tidal current direction, trawl alignment, and day and night periods. J. exp. mar. Biol. Ecol. 38: 247-260

Fuss, C. M. Jr, Ogren, L. H. (1966). Factors affecting activity and burrowing habits of the pink shrimp, Penaeus duorarum Burkenroad. Biol. Bull. 130: 170-191

Gamba, A. L., Rodriguez, G. (1987). Migratory behavior of postlarval white, Penaeus schmitti, and river shrimps, Macrobrachium olfersi and Macrobrachium acanthurus, in their zone of overlap in a tropical lagoon. Bull. mar. Sci. 40: $454-463$

Graham, J. M., Bowers, R., Gibson, R. N. (1987). A versatile tide machine and associated activity recorder. J. mar, biol. Ass. U.K. 67: 709-716

Hill, B. J. (1985). Effect of temperature on duration of emergence, speed of movement, and catchability of the prawn Penaeus esculentus. In: Rothlisberg, P. C., Hill, B. J., Staples, D. J. (eds.) Second Aust. Nat. Prawn Sem., NPS2, Cleveland, Australia, p. 77-83

Hindley, J. P. R. (1975). Effects of endogenous and some exogenous factors on the activity of the juvenile banana prawn Penaeus merguiensis. Mar. Biol. 29: 1-8

Howard, R. K., Lowe, K. W. (1984). Predation by birds as a factor influencing the demography of an intertidal shrimp. J. exp. mar. Biol. Ecol. 74: 35-52

Hughes, D. A. (1968). Factors controlling the emergence of pink shrimp (Penaeus duorarum) from the substrate. Biol. Bull. 134: $48-59$

Hughes, D. A. (1969). Responses to salinity change as a tidal transport mechanism of pink shrimp, Penaeus duorarum. Biol. Bull. 136: 43-53

Hughes, D. A. (1972). On the endogenous control of tideassociated displacements of pink shrimp. Penaeus duorarum Burkenroad. Biol. Bull. 142: 271-280

Kutty, M.N., Murugapoopathy, G. (1968). Diurnal activity of the prawn Penaeus semisulcatus de Haan. J. mar. biol. Ass. India 10:95-98

Lakshmi, G. J., Venkataramiah, A., Gunter, G. (1976). Effects of salinity and photoperiod on the burying behaviour of brown shrimp Penaeus aztecus Ives. Aquaculture 8: $327-336$

Minello, T. J., Zimmerman, R. J., Martinez, E. X. (1987). Fish predation on juvenile brown shrimp. Penaeus aztecus Ives: effects of turbidity and substratum on predation rates. Fish. Bull. U.S. 85: 59-70

Moller, T. H. Jones, D. A. (1975). Locomotory rhythms and burrowing habits of Penaeus semisulcatus (de Haan) and
P. monodon (Fabricius) (Crustacea: Penaeidae). J exp. mar. Biol. Ecol. 18: 61-77

Mukherjee, A. K. (1971). Food habits of water birds of the Sundarban, 24-Parganas District, West Bengal, India. II. Herons and Bitterns. J. nat. Hist. Soc. Bombay 68: $37-64$

Natarajan, P. (1989a). Persistent locomotor rhythmicity in the prawns Penaeus indicus and P. monodon. Mar. Biol. 101: $339-346$

Natarajan, P. (1989b). External synchronizers of tidal activity rhythms in the prawns Penaeus indicus and $P$. monodon. Mar. Biol. 101: 347-354

Racek, A. A. (1959). Prawn investigations in eastern Australia. Res. Bull. State Fish. N.S.W. 6: 1-57

Reid, D. G., Bolt, S. R. L., Davies, D. A., Naylor, E. (1989). A combined tidal simulator and actograph for marine animals. J. exp. mar. Biol. Ecol. 125: 137-143

Reynolds, W. W., Casterlin, M. E. (1979). Diel activity of the pink shrimp Penaeus duorarum. Hydrobiologia 66 : $223-226$

Salini, J. P., Blaber, S. J. M., Brewer, D. T. (1990). Diets of piscivorous fishes in a tropical Australian estuary, with special reference to predation on penaeid prawns. Mds. Biol. 105: 363-374

SAS Institute Inc. (1988). SAS/STAT user's guide, Release 6.03 edn. SAS Institute Inc., Cary, NC

Snedecor, G. W., Cochran, W. G. (1978). Statistical methods. The lowa State University Press, Ames

Staples, D. J., Vance, D. J. (1979). Effects of changes in catchability on sampling of juvenile and adolescent banana prawns, Penaeus merguiensis de Man. Aust. J. mar. Freshwat. Res. 30: 511-519

Staples, D. J., Vance, D. J., Heales, D. S. (1985). Habitat requirements of juvenile penaeid prawns and their relationship to offshore fisheries. In: Rothlisberg, P. C., Hill, B. J., Staples, D. J. (eds.) Second Aust. Nat. Prawn Sem., NPS2, Cleveland, Australia, p. 47-54

Subrahmanyam, C. B. (1976). Tidal and diurnal rhythms of locomotory activity and oxygen consumption in the pink shrimp, Penaeus duorarum. Contr. mar. Sci. 20: 123-132

Trent, L. (1966). Size of brown shrimp and time of emigration from the Galveston Bay system, Texas. Proc. Gulf Carib. Fish. Inst., 19th Ann. Sess. Univ. of Miami Marine Laboratory, Coral Gables, p. 7-16

Underwood, A. J. (1972). Sinusoidal tide models: design, construction and laboratory performance. J. exp. mar Biol Ecol. 8: 101-111

Vance, D. J., Haywood, M. D. E., Staples, D. J. (1990). Use of a mangrove estuary as a nursery area by postlarval and juvenile banana prawns, Penaeus merguiensis de Man, in northern Australia. Estuar. coast. Shelf Sci. 31: 689-701

Vance, D. J., Staples, D. J. \{1992\}. Catchability and sampling of three species of juvenile penaeid prawns in the Embley River, Gulf of Carpentaria, Australia. Mar. Ecol. Prog. Ser. 87: $201-213$

White, T (1975). Factors affecting the catchability of a penaeid shrimp, Penaeus esculentus. In: Young, P. C. (ed.) First Aust. Nat. Prawn Sem. AGPS, Canberra, p. 115-137

Wickham, D. A. (1967). Observations on the activity patterns in juveniles of the pink shrimp, Pendeus duorarum. Bull. mar. Sci. 17: 769-786

Young, P. C. (1975). Preliminary observations on the environment and biology of juvenile king prawns (Pendeus plebejus) in Moreton Bay, Queensland. In: Young, P. C. (ed.) First Aust. Nat. Prawn Sem. AGPS, Canberra, p. 18-36 